Global Journal of Pure and Applied Mathematics.

ISSN 0973-1768 Volume 15, Number 6 (2019), pp. 1055-1067

(C) Research India Publications

https://dx.doi.org/10.37622/GJPAM/15.6.2019.1055-1067

\title{
Soft Sets - Motivation and Overview
}

\author{
B.V.S.T.Sai*，P.D.N.Srinivasu, N.V.E.S.Murthy \\ Department of Mathematics A.U. College of Science and Technology Andhra \\ University, Visakhapatnam-530003, A.P. State, India.
}

\begin{abstract}
In this paper we present some of the main developments in the soft set theory as well as in the theory of algebraic structures and soft topology as a review of literature motivated by Molodsov.
\end{abstract}

Keywords: Soft set, Fuzzy Soft set, Soft operations, Soft algebraic structures and Soft Topological Spaces.

\section{INTRODUCTION}

The problem of uncertainty or vagueness has been tackled for several years by philosophers, logicians, mathematicians and computer scientists. Many practical problems in engineering, economics, social science, environmental science, and medical science etc., cannot be resolved by classical methods due to these methods inherent difficulties such as inadequacy of the theories of parameterization tools.

To understand and manipulate imperfect knowledge there are many ways and the most successful approach to tackle this problem is the Fuzzy set theory. In 1965 L. A. Zadeh[102] introduced Fuzzy set theory and he described the control problems of complex systems and dealing with fuzzy system. The idea and the concept of Fuzzy set were introduced by Zadeh and he used the unit interval $[0,1]$ to describe

\footnotetext{
* Corresponding Author
} 
and deal with fuzzy phenomena.

In 1982, P.Pawlak[81] proposed the rough set theory as an important mathematical tool to deal with imprecise, inconsistent, incomplete information and knowledge.

Molodtsov[56] introduced the new concept of Soft Set as a completely generic mathematical tool for modeling uncertainties. There is no limited condition to the description of objects, so researchers can choose the form of parameters they need, which greatly simplifies the decision-making process and make the process more efficient in the absence of partial information.

Ever since the soft sets came into existence, some mathematicians started imposing and studying algebraic structures on soft sets. Since any soft set involves two component sets, namely, a universal set and a parameter set, interestingly, some researchers algebrized universal set and others algebrized parameter set.

\section{A BRIEF REVIEW ON SOFT SETS}

In 1999 D. Molodtsov[56] introduced the Soft set theory as a general mathematical tool for dealing with uncertainty or vagueness. In his pioneering paper Soft Set Theory- First Results which was published in the journal Computers and Mathematics with Applications.

\subsection{Algebraic operations on soft sets}

In 2003 Maji[49,51] presented some new definitions on Soft sets and discussed the application of Soft set theory in decision making problems. They also defined the concepts of equality of two soft sets, absolute soft set and null soft set.

In 2009 Irfan-Fu[6,7,8] presented some new notions on soft set theory. In 2010 Babitha-Sunil [15] presented the concept of soft set relations and introduced as a sub soft set of the Cartesian product of the soft sets. Majumdar-Samanta[52] introduced and studied various properties of soft mappings, images and inverse images of soft mappings. Xiao[99] proposed the notion of exclusive disjunctive soft sets and studied some of its operations Gong[32] proposed the concept of bijective soft set and some of its operations and also discussed an application of bijective soft set in decisionmaking problem.

In 2011 Sezgin[89] defined the notion of restricted symmetric difference of soft sets and investigated its properties. Babitha-Sunil[14] introduced antisymmetric relation and transitive closure of a soft set relation and proposed Warshall's algorithm. Pal-Mondal[77] characterized soft matrices based on soft set and defined 
operations of soft matrices.Yang- Guo[101] introduced the notions of anti-reflexive kernel, symmetric kernel, reflexive closure and symmetric closure of a soft set relation.

In 2012 Min[55] studied the concept of similarity between soft sets which is an extension of the equality for soft set theory. Singh-Onyeozili $[75,93,94]$ presented the main objective and clarified some conceptual misunderstandings of the fundamentals of soft set theory and investigated some distributive and absorption properties of operations on soft sets. Ali discussed the idea of reduction of parameters in case of soft sets and studied approximation space of Pawlak associated with a soft set. Park[78] studied the equivalence soft set relations and obtained soft analogues of many results concerning ordinary equivalence relations and partitions. In 2013 FengAli-Shabir[26] introduced the concepts of soft binary relations and some related properties are investigated on Soft semigroups. In 2014 Xin-Li[100] initiated the study of soft congruence relations by using the soft set theory.

\subsection{Some Algebraic Structures on Soft sets}

In 2007 the algebraic nature of set theories dealing with uncertainties has been studied by some authors like Aktas-Cagman. Aktas-Cagman[5] compared Soft sets to the related concepts of Fuzzy sets and Rough sets. And also defined the notion of soft groups and derived some properties. In 2009 Ali[8] studied some important properties associated with these new operations. A collection of all soft sets with respect to new operations give rise to four idempotent monoids. Sezgin-Atagun[91] introduced Soft groups and normalistic soft groups.

In 2014 Aktas-Ozlu[4] introduced order of the soft groups and some of the properties are investigated. Ali-Shabir[9] and Murthy-Maheswari[66,68,69,71] considered various soft substructures over a given semigroup and obtained some interesting properties.

In 2008 Feng[27] introduced the notions of soft semirings. In 2010 Acar[1] introduced initial concepts of soft rings. Ozturk-Inna[76] presented soft-rings and idealistic soft rings. In 2011 Celik[18] studied soft rings and ideals. Qiu-Sun[97] introduced the definition of soft modules and constructed some basic properties. Atagun-Sezgin[11] introduced soft subfields of a field and soft submodule of a left R-module and proposed their related properties. Xin- Li[100] introduced the notions of soft quotient rings, generalized soft ideals and generalized soft quotient rings and several related properties are investigated. Also, they obtained a one- to-one correspondence between soft congruence relations and idealistic soft rings and a oneto-one correspondence between soft congruence relations and soft ideals. In 
particular, the first, second and third soft isomorphism theorems are established. In 2011 Sezgin-Atagun- Ayugn[90] investigated the properties of idealistic soft nearrings with respect to the near-ring mappings and they have shown that the structure is preserved under the near-ring epimorphisms.

One can refer Changphas-Thongkam[19] for soft algebras in a general viewpoint. Jun[37] applied the notion of soft sets to the theory of BCK/BCI- algebras and introduced soft sub algebras then derived their basic properties with some illustrative examples. Jayalakshmi- Subbiah[34] introduced the notion of soft T-ideals and Tidealistic soft BCI-algebras and relations between fuzzy T-ideals and T-idealistic soft BCI-algebras are discussed. Jun-Lee- Park[38] introduced the notions of soft dalgebras, their related properties are surveyed. Park [39] introduced soft WS-algebras and explored their basic properties and Jun-Park[35] introduced the concept of soft Hilbert algebra, soft Hilbert abysmal algebra and soft Hilbert deductive algebra and investigated their properties. Fu Li[28], E.K.R.Nagarajan[73], Karaaslan[42] defined the soft Lattice and studied their algebraic properties and characterization theorems. Jun-Lee-Zhan[40] introduced soft p-ideals of soft BCI-algebras. Zhu [103] introduced soft BL-algebras and soft logic system. Kurt[16] developed soft algebraic structures. Kazanci-Yilmaz-Yamak[43] established soft BCH-algebras. JunSun[36] proposed soft sets in BE-algebras. Alshehri-Akram-Al-ghamdi[10] introduced soft K- algebras. Soft abstract algebras were introduced and studied in Khameneh-Kilicman[44] and Murthy-Maheswari[58,60,61,62,65]. In 2013 DasSamantha[22] presented an idea of soft inner product on soft linear spaces and some of their properties are investigated. Soft Hilbert spaces, orthogonality and orthonormality in soft Hilbert spaces are also studied. In 2014 Das- Samantha[24] introduced Soft vectors in soft linear spaces and their properties are investigated.

In 2017, Murthy-Maheswari[64] generalized the notion of soft set to that of a generalized soft set, deriving its theory from f-Set Theory of Murthy[59] in 1997, generalizing the soft (inverse) image of a soft subset under a soft map to that of a generalized soft (inverse) image of a generalized soft subset under a generalized soft map which now exist between soft sets with different universal sets.

In 2019 Murthy-Maheswari[70] proved that for any soft set over a universal set, there is a crisp set in such a way that the complete lattice of all soft subsets of the former is complete epimorphic to a complete lattice of certain subsets of the later crisp set. Further, in Murthy-Maheswari[63] and Murthy-Gouthami[72] similar results were proved for both Semigroups and Groups.

In 2001 Maji-Biswas-Roy[50] introduced the notion of fuzzy soft set by fuzzyfying the soft set and defined some basic operations on these sets. They also studied some 
algebraic properties of these operations and discussed in detail an application of fuzzy soft set theory in a decision making problem. In 1991 Murali[57] introduced the notion of fuzzy subalgebras of a given algebra in the universal algebraic sense and studied some (lattice) algebraic properties of the collection of all fuzzy subalgebras of the same type as the given algebra and showed that this set forms a complete lattice. In 2009 Aygunoglu-Aygun[12] introduced the notions of fuzzy soft group, normal fuzzy soft group and studied their algebraic properties.

In 2011 Manemaran[53] defined operations on fuzzy soft groups and proved some results of them. In 2011 Ghosh-Dinda-Samanta[30] introduced the notions of fuzzy soft ring, fuzzy soft ideal and studied their algebraic properties. In 2012 VarolAygunoglu-Aygun[82] introduced the notion of fuzzy soft ring, fuzzy soft ideal, idealistic fuzzy soft ring and studied their algebraic properties.

\subsection{Soft Topological Spaces}

In 1968 Chang was the first person who studied about the topological structures of Fuzzy set theory dealing with uncertainties. He introduced the notion of Fuzzy Topology and also studied some of its basic properties.

In 2011 Shabir-Naz[92] initiated the study of soft topological spaces. Min[54] investigated the soft regular spaces and some properties of them. HussainAhmad[3] discussed the most fundamental concepts of soft topological structures. Min[54] investigated the properties of soft regular spaces.

In 2012 Mahanta-Dass[48] studied in detail about semi open soft set, semi closed soft set, semi continuity, semi connectedness, semi compactness and semi separation axioms in Soft set theory. Das-Samanta [23] introduced a notion of soft metric, and alsoestablished completeness of soft metric spaces and Cantor's intersection theorem in soft metric space setting. Nazmul-Samanta[74]introduced several notions such as soft topological soft groups, soft topological soft normal subgroups and soft topological soft factor groups and studied their properties. Aygünoğlu-Aygün[13] defined soft product topology and studied the properties of soft projection mappings. Also they defined soft compactness and generalized Alexander subbase theorem and Tychonoff theorem to the soft topological spaces. Kannan[41] introduced soft generalized closed sets in soft topological spaces which are defined over an initial universe with a fixed set of parameters and its basic properties are investigated.

In 2013 Georgiou[29] studied the theory of soft topological spaces and presented some new definitions. Chen[20,21] introduced some local properties by soft semiopen sets, soft semi-neighborhoods of the soft point and some of their properties are studied in the paper "Some Local Properties of Soft Semi-Open Sets". 
Wardowski[98] introduced a new notion of soft element of a soft set and established its natural relation with soft operations and soft objects in soft topological spaces. Krishnaveni-Sekar[47]introduced the soft semi separation of soft sets and exhibited some properties.

In 2014 Subhashinin-Sekar[96] introduced soft pre T1 space in the soft topological spaces. Peyghan-Samadi-Tayebi[84] considered the concepts of soft compactness and countably soft compact and obtained some results. Then they studied some soft separation axioms that have studied by Min-Naz, by constructing some examples to show that some classical results in general topology are not true about soft topological spaces, for instance every compact Housdorff space need not be normal.

In 2013 Sai-Srinivasakumar[86,87] introduced Soft semi-topology on the collection of all Soft semi-open sets over a fixed universe set. The concept of soft semi-limit is introduced and its relationship with soft semi closure is discussed. The soft separability and soft semi separability are introduced and they are shown to be equivalent and the concept of soft relative topology is introduced. In 2014 [95], they constructed a soft topology over universe set $X$ by assigning a topological structure to $X$ and probed some interesting results in this context. Assigning some structure to the universe set and verifying its consequences in the resulting soft set theory as a new approach and this area has a scope for further research. In 2016[85], they presented the two approaches of soft topology and the comparison between them. They first presented Cagman's[17] approach of soft topology and later they discussed Shabir-Naz's[92] theory of soft topological space. Finally they compared these two approaches. Further they presented some topological properties and introduced the concept of soft second countability.

\section{CONCLUSION}

In this paper we have presented a detailed theoretical study on soft sets. We successfully observed algebraic operations, some algebraic structures, soft topological spaces and their basic properties on soft sets which are established by so many authors. This paper stating soft mathematical concepts of structures that are based on soft set theoretic operations .Hence we can expect that some research teams will be actively working on soft algebraic and topological structures.

\section{ACKNOWLEDGMENTS}

The first author expresses his gratitude and indebtedness to the second and third authors for their immeasurable support and abundant advice in completing this paper. 


\section{REFERENCES}

[1] Acar, U., Koyuncu, F. and Tanay, B. "Soft sets and soft rings", Comput. Math. Appl59, 3458-3463, 2010.

[2] Ahmad, B. and Kharal, A. "On fuzzy soft sets, Advances in Fuzzy Systems", Hindawi Publishing Corporation, doi:10.1155/2009/5865072009.

[3] Ahmad.B and Hussain.S, "On Some Structures of Soft Topology", Mathematical Sciences 6:64, 2012.

[4] Aktas.H.J.,“Cyclic Soft Groups and Their Applicationson Groups”,Hindawi Publishing Corporation Scientific World Journal, Vol 2014, Article ID 437324, 5 pages, 2014.

[5] Aktas.H, Cagman.N, "Soft sets and soft groups", Information Sciences, Vol.177, pp.2726-2735, 2007.

[6] Ali, M.I. and Shabir, M. "Comments on De Morgan's law in fuzzy soft sets", J. Fuzzy Math. 18, 679-686, 2010.

[7] Ali, M.I. and Shabir, M. "Logic connectives for soft sets and fuzzy soft sets", IEEE Transactions on Fuzzy Systems 22 (6), December 2014.

[8] Ali, M.I., Feng, F., Liu, X., Min, W.K. and Shabir, M. "On some new operations in soft set theory", Comput. Math. Appl. 57, 1547-1553, 2009.

[9] Ali.M.I , Shabir.M and Shum.K.P, "On Soft Ideals over Semigroups", Southeast Asian Bulletin of Mathematics, 34, 595-610, 2010.

[10] Alshehri, NO, Akram, M, Al-ghamdi, "Applications of Soft Sets in KAlgebras". Advances in Fuzzy systems, Hindawi Publishing Corporation, RS 2013.

[11] Atagun, A.O. and Sezgin, A. "Soft substructures of rings, fields and modules", Comput. Math. Appl. 61, 592-601, 2011.

[12] Aygunoglu.A and Aygun.H, "Introduction to fuzzy soft groups", Comput. Math. Appl. 58 , 1279-1286,2009.

[13] Aygunoglu.A and Aygun.H., "Some notes on soft topological spaces", Vol 21, Supplement 1, pp 113-119,2012,.

[14] Babitha.K.V \& Sunil.J.J, "Transitive Closure and Ordering on Soft Sets", Computers \& Mathematics with Applications, Vol. 60, Pp.2235-2239,2011.

[15] Babitha.K.V \& Sunil.J.J., "Soft Set Relations and Functions", Computers and Mathematics with Applications, Vol. 60, No. 7, Pp.1840-1849,2010. 
[16] Burak Kurt, "On the soft sets and algebraic structures", Int. Journal of Math. Analysis 7, 2689-2695, 2013.

[17] Cagman.N, Karatas.S and Enginoglu.S,'"Soft Topology", Comput. Math. Appl. 62,351-358,2011.

[18] Celik.Y.,"A New View on SoftRings",Hacettepe Journal of Mathematics and Statistics, Vvol. 40, Pp. 273-286,2011.

[19] Changphas, T. and Thongkam, B. "On soft algebras in a general viewpoint", Int. J.Algebra 6, 109-116, 2012.

[20] Chen. B., "Soft Semi-open Sets and related properties in Soft Topological Spaces”, Appl. Math. Inf. Sci., Vol-7, No-1, pp. 287-294, 2013.

[21] Chen. B., "Some Local Properties of Soft Semi-Open Sets", Discrete Dynamics in Nature and Society,Vol-2013,pp.1-6,2013.

[22] Das.S and Samanta.S.K, "On Soft Inner product Spaces", Ann. Fuzzy Math. Inform, 6(1), 151-170,2013.

[23] Das.S and Samanta.S.K, "Soft metric", Ann. Fuzzy Math. Inform. 6(1), 7794,2013.

[24] Das.S, Majumdar.P and Samanta.S.K, "On soft linear spaces and soft normed linear spaces", arXiv:1308.1016 [math.GM]

[25] Dickson.L.E, "On semi-groups and the general isomorphism between infinite groups", Transactions of the American Mathematical Society, 6,205208, 1905.

[26] Feng, F., Ali, M.I. and Shabir, M., "Soft relations applied to semigroups", Published by Faculty of Sciences and Mathematics,University of Ni's, Serbia Filomat ,27,1183,1196,2013.

[27] Feng, F., Jun, Y.B. and Zhao, X., "Soft semi rings", Computers \& Mathematics with Applications, Vol.56, pp.2621-2628, 2008.

[28] FuLi , "Soft Lattices", Global Journal of Science Frontier Research, Vol. 10, Pp.57-59,2010.

[29] Georgiou. D. N., Megaritis. A.C, and Petropoulos, "On Soft Topological Spaces”, Appl. Math. Inf. Sci., Vol-5, pp.1889-1901, 2013.

[30] Ghosh.J, Dinda.B and Samanta.T.K, "Fuzzy soft rings and fuzzy soft ideals', Int. J.Pure Appl. Sci. Technol. 2(2), 66-74,2011.

[31] Goguen, J.A. "L-Fuzzy sets", J Math Anal Appl 18, 145-174, 1967. 
[32] Gong .K, "The Bijective Soft Set with its Operations", Computers and Mathematics with Applications, Vol. 60, Pp.2270-2278,2010.

[33] Good.R.A and Hughes.D.R, “Associated groups for a semigroup”, Bull.Amer. Math. Soc., 58, 624-625, 1952.

[34] Jayalakshmi, D and Subbiah, G.,"Soft T-ideals of Soft BCI-Algebras" International Journal of Mathematics Trends and Technology, 65(1), 31-39, 2019.

[35] Jun, Y.B, and Park.C.H. , "Application of Soft Sets in Hilbert Algebras", Iranian Journal of Fuzzy Systems, Vol. 6, No. 2, Pp.75-86,2009.

[36] Jun, Y.B. and Ahn, S.S. "Applications of soft sets in BE-algebras, Algebra", Hindawi Publishing Corporation, 2013.

[37] Jun, Y.B. "Soft BCK/BCI-algebras", Comput. Math. Appl. 56, 1408-1413, 2008 .

[38] Jun, Y.B., Lee, K.J. and Park, C.H. "Soft set theory applied to ideals in d-algebras",Comput. Math. Appl. 57, 367-378, 2009.

[39] Jun, Y.B., Lee, K.J. and Park, C.H." Soft Ws-Algebras" Commun. Korean Math. Soc. 23, No. 3, pp. 313-324,2008.

[40] Jun, Y.B., Lee, K.J. and Zhan, J. "Soft p-ideals of soft BCI-algebras", Comput. Math. Appl. 58, 2060-2068, 2009.

[41] Kannan.K, "Soft Generalized Close Sets in Soft Topological Spaces", Journal of Theoretical and Applied Information Technology 37(1), 1720,2012 .

[42] Karaaslan.F, "Soft Lattices", Journal of New Results in Science, Vol. 1, Pp.5-12,2012.

[43] Kazanci.O, Yilmaz.S, and Yamak.S, "Soft sets and soft BCH-algebras", Hacet. J. Math. Stat. 39 (2), 205-217, 2010.

[44] Khameneh.A.Z. and Adem Kilicman. A.” On soft $\sigma$-algebras", Malays. J. Math. Sci. 7, 17-29, 2013.

[45] Kharal, A, Ahmad, B . "Mappings on soft classes". arXiv, 1006.4940v1[math.LO] 25 Jun.2010.

[46] Kharal, A, Ahmad, B . "Mappings on soft classes". New Math \&NatComp, 7(3), 471- 482,2011.

[47] Krishnaveni.J , Sekar.C," Soft semi connected and Soft locally semi connected properties in Soft topological spaces", International Journal of 
Mathematics and Soft Computing, , ISSN 2249-3328,vol 3,No 3,85-91,2013.

[48] Mahanta. J., and Das. P. K., “ On Soft Topological Space Via Semi-open and Semi- closed Soft Sets", Math. GN, Vol-14, pp. 1-8, 2012.

[49] Maji.P. K, Biswas.R and Roy.A. R . "An application of soft sets in a decision making problem". Comput Math Appl, 44(8-9), 1077-1083,2002.

[50] Maji.P. K, Biswas.R and Roy.A. R, "Fuzzy soft sets", J. Fuzzy Math. 9 , 589-602,2001.

[51] Maji.P. K, Biswas.R and Roy.A. R, "Soft set theory", Computers \& Mathematics with Applications, Vol.45, pp.555-562, 2003.

[52] Majumdar.P\&Samanta.S.K, “On SoftMappings”,Computers\& Mathematics with Applications, Vol. 60, Pp. 2666-2674,2010.

[53] Manemaran, S.V. "On fuzzy soft groups", International Journal of Computer Applications, 15(7), 38-44, 2011.

[54] Min.K.W.,"A Note on Soft Topological Spaces", Comp. Math. Appl., Vol-62, pp. 3524-3528, 2011.

[55] Min.W.K, "Similarity in Soft Set Theory", Applied Mathematics Letters, Vol. 25, Pp.310-314,2012.

[56] Molodtsov.D, "Soft set theory-first results”, Comput. Math. Appl., 37, 19-31, 1999.

[57] Murali.V, "Lattice of fuzzy subalgebras and closure systems in IX, Fuzzy Sets and Systems" 41, pp101-111, 1991.

[58] N.V.E.S. Murthy and Ch. Maheswari. "A first study of f-(fuzzy) soft $\tau$ algebras and their f-(fuzzy) soft $\boldsymbol{\omega}$-subalgebras", Global Journal of Pure and Applied Mathematics, 13(6), pp.2503-2526, 2017.

[59] N.V.E.S. Murthy, "Is the axiom of choice true for fuzzy sets?". Journal of Fuzzy Mathematics, 5(3), pp495-523, U.S.A., 1997.

[60] N.V.E.S. Murthy and Ch. Maheswari "A lattice theoretic study of $f$ (fuzzy) soft-algebras and theirf-(fuzzy) soft subalgebras", Communicated.

[61] N.V.E.S. Murthy and Ch. Maheswari, "Maximal p-soft -subalgebras and psoft -homomorphisms of p-soft $\tau$-algebras", (comunicated).

[62] N.V.E.S. Murthy and Ch. Maheswari," An An Elemetary Study of p-fuzzy soft $\tau$ - algebras and their p-fuzzy soft $\boldsymbol{\omega}$-subalgebras", Advances and Applications in mathematical Sciences, Vol.18, Issue 5, pp 437-459, 2019. 
[63] N.V.E.S. Murthy and Ch. Maheswari, "Representation of soft substructures of a soft semigroup by products", Int. J. Sci. Research in Math. Stat. Sci., pp.172-181, 2019.

64] N.V.E.S. Murthy and Ch. Maheswari, "A Generalized Soft Set Theory from f-Set Theory". Advances in Fuzzy Mathematics 12(1), 1-34, 2017.

[65] N.V.E.S. Murthy and Ch. Maheswari, "An Introduction to p-soft $\tau$-algebras and their p-soft w-subalgebras", International Journal of Computational and Applied Mathematics 12(2), 615-629, 2017.

[66] N.V.E.S. Murthy and Ch. Maheswari, "A note on regular soft substructures of a soft semigroup", IJMTT, Vol.65, issue.5, pp.92-99, 2019.

[67] N.V.E.S. Murthy and Ch. Maheswari, "A Remark on Factorizable substructures of a product semigroup", JASC, Vol.6, Issue .4, pp 3278-3286, 2019.

[68] N.V.E.S. Murthy and Ch. Maheswari, "A Note on 0-Adjoined Soft Semigroups", (Communicated).

[69] N.V.E.S. Murthy and Ch. Maheswari, "A Note on the Extensions of the Soft Substructures of a Soft Semigroup", J.Int.Math.Virt.Inst, Vol.10, pp.41-58, 2019.

[70] N.V.E.S. Murthy and Ch. Maheswari, "Representation of Soft Subsets by Products", International Journal of Mathematics And its Applications, Vol.6, Issue 2-A, pp.227-241, 2018.

[71] N.V.E.S. Murthy and E. Gowthami, "Generalized Soft Substructures of Genralized Soft Semigroups" (Communicated).

[72] N.V.E.S. Murthy and E. Gowthami, "Representation of Soft Substructures of a soft Group", (Communicated)

[73] Nagarajan.E.K.R and Meenambigai.G,“An Application of SoftSets to Lattices",KragujevacJournal of Mathematics, Vol. 35, No. 1, Pp. 75-87,2011.

[74] Nazmul.S.K and Samanta.S.K, "Soft topological soft groups", Nazmul and Samanta Mathematical Sciences ,6:66,2012.

[75] Onyeozili. I.A, Gwary. T.M . "A study of the fundamentals of soft set theory". International Journal of Scientific and Technology Research, 3, 132143.2014 .

[76] Ozturk.M.A and Inna.E, "Soft-Rings and Idealistic Soft Rings", Annuals 
of Fuzzy Mathematics and Information, Vol. 1, No. 1, Pp.71-80,2011.

[77] Pal.M and Mondal.S, "Soft Matrices", African Journal of Mathematics and Computer Science Research, Vol. 4, No. 13, Pp.379-388,2011.

[78] Park.J.H.,"Some Properties of Equivalence SoftSet Relations",Computers and Mathematics with Applications, Vol. 63, Pp.1079-1088,2012.

[79] Pawlak.Z, "Hard Set and Soft Sets", ICS Research Report, Institute of Computer Science,1994.

[80] Pawlak.Z,"Hard and Soft Sets", International Journalof Computer \& Information Sciences, Vol. 11, No. 5, Pp.341-356,1982.

[81] Pawlak.Z, "RoughSets", International Journal of Computer and Information Science,Vol.11,Pp.341-356,1982.

[82] Pazar Varol, B., Aygunoglu, A. and Aygun, H. "On fuzzy soft rings", Journal of Hyperstructures 1, 1-15, 2012.

[83] Pei.D. and Miao.D, "From soft sets to information systems", Proceedings of Granular Computing, IEEE InternationalConference 2, 617- 621. 2005.

[84] Peyghan.E, Samadi.B and Tayebi.A, "About Soft Topological Spaces", Journal of New Results in Science 2, 60-75.2013.

[85] Sai.B.V.S.T, "A Comparative study of Cagman'sand Shabir- Naz'sTheory of Soft Topology", International Journal of Modern Sciences and Engineering Technology (IJMSET),ISSN 2349-3755 Vol 3, Issue 4, pp.37-41, 2016.

[86] Sai.B.V.S.T, and Srinivasakumar.V, "On Soft Semi-Separability", International Journal of Mathematical Analysis, Vol-7, pp.2663-2669,2013.

[87] Sai.B.V.S.T, and Srinivasakumar.V., "On Soft Semi-Open Sets and Soft Semi-Topology", International Journal of Mathematical Archive, Vol4,No.3, pp.114-117, 2013.

[88] Sai.B.V.S.T., "Some algebraic operations of Soft set theory",International Journal of Modern Sciences and Engineering Technology (IJMSET) ISSN 2349-3755; vol 3, Issue 4, pp.53-56, 2016.

[89] Sezgin.A and Atagun.A.O . "On operations of soft sets". Comput Math Appl, 61(5), 1457-1467.2011.

[90] Sezgin.A and Atagun.A.O and Ayugn, E." A note on soft near-rings and idealistic soft near-rings", Filomat 25, 53-68, 2011.

[91] Sezgin.A and Atagun.A.O, "soft groups and normalistic soft groups", 
Comput. Math. Appl. 62, 685-698.2011.

[92] Shabir.M and Naz.M., "On Soft Topological Spaces", Comput. Math. Appl. 61, 186-199.2011.

[93] Singh. D, Onyeozili.I.A ., "On some new properties of soft set operations". International Journal of Computer Applications, 59, 39-44.2012.

[94] Singh.D and Onyeozili.I.A, "Some Conceptual Misunderstandings of the Fundamentals of Soft Set Theory", A.R.P.N. Journal of Systems and Software, Vol. 2, No.9,2012.

[95] Srinivasakumar.V, and B.V.S.T. Sai., "A Novel Approach: Soft Topology", GAPAM, Vol-10, pp. 443-449, 2014.

[96] Subhashinin.J and Sekar.C, "Soft pre T1 Space in the Soft Topological Spaces", International Journal Of Fuzzy Mathematics And Systems, Vol. 4, No.2, Pp.203-207,2014.

[97] Sun.Q.M, Zhang.Z.L and Liu.J, "Soft sets and soft modules", Proceedings of Rough Sets and Knowledge Technology, Third International Conference RSKT, 403-409,2008.

[98] Wardowski.D, "On a soft mapping and its fixed points”, Wardowski Fixed Point Theory and Applications :182,2013.

[99] Xiao.Z,"Exclusive Disjunctive SoftSets", Computers \& Mathematics with Applications, Vol. 59, Pp. 2128-2137,2010.

[100] Xin.X and Li.W, "Soft Congruence Relations over Rings",Hindawi Publishing Corporation Scientific World, Vol 2014, ArticleID541630, 9pages,2014.

[101] Yang.H\&Guo.Z,"Kernels and Closures of SoftSet Relations and SoftSet Relation Mappings",Computers\& Mathematics with Applications, Vol. 61, Pp. 651-662,2011.

[102] Zadeh.L.A., "Fuzzy sets", Information and Control, Vol.8, pp.338-353.1965.

[103] Zhu.Z, "Soft sets, soft BL-algebras and soft logic system BL", Procedia Engineering 15, 3531-3535, 2011. 
